\title{
'Speaking' with other animals through intuitive interspecies communication: towards cognitive and interspecies justice
}

\author{
M.J. Barrett, Viktoria Hinz, Vanessa Wijngaarden and \\ Marie Lovrod
}

\section{Introduction}

Intuitive exchanges between humans and other species constitute a form of interspecies communication that has been experienced and practised widely over time and across cultures. Yet its uptake in academe has been slow, given the tricky terrain of knowledge and species hierarchies, together with a pervasive, socially constructed separation between humans and other beings. Anthropocentrism (human-centredness) and human exceptionalism (the valuing of humans above other animals ${ }^{1}$ based on purportedly superior traits) (Anderson, 2014) both reinforce this inaccurate and instrumentalist positioning, thwarting cognitive justice across species. In efforts to respect more-than-human animals as subjects, scholars studying animal geographies, together with colleagues from fields such as, but not limited to, environmental education, Indigenous studies, anthropology, feminist critical animal, trans-species, multispecies and human-animal studies, are seeking ways to engage animal voices in their research, educational practices and everyday lives (Bear, 2017; Blenkinsop et al., 2017; Buller, 2015; Deloria, 2006; Dowling et al., 2016; Fawcett, 2000; Gibbs, 2019; Hamilton and Taylor, 2017; Haraway, 2004, 2008; McGinnis et al., 2019; Taylor and Hamilton, 2014). For many animal studies scholars, the aim is to achieve 'a portrait of shared existence' (Lorimer, 2010: 73) and co-becoming (Haraway, 2008) that does not contribute unwittingly to the oppression of non-human beings (Anderson, 2014). Central to 
this endeavour is often the question of how we humans can better understand other animals' perspectives, as well as explore existing and deepened ways of communicating across species.

This chapter focuses on the experience of immediate two-way communication between humans and other animals that is independent of physical proximity. We begin by positioning ourselves, describing intuitive interspecies communication (IIC), ${ }^{2}$ and reviewing current research on multispecies methods and IIC literature. Using illustrative results from a review of relevant books and websites in English, we then introduce those who practise IIC professionally as 'animal communicators'. These individuals have a specialized set of skills that could contribute to future multispecies research efforts. Subsequently, we offer advice for those interested in the method, based on our own experiences as researchers and learners of IIC. We close by identifying how IIC can contribute to justice for and with animals as part of a promising research agenda for animal geographies committed to increasing capacities to conduct research with, rather than on, animals.

As authors and researchers, we seek to deepen understandings of animals' perspectives by engaging IIC to disrupt human tendencies to speak 'for' animals. Too often this occurs without consulting them, and with short-sighted vested interests in discounting animals' perspectives, roles, needs and potentials for mutual flourishing. We recognize that aspects of this topic share some epistemological, ontological and axiological similarities with interspecies communication in Indigenous contexts (Deloria, 2006). Some animal communicators have learned from Indigenous mentors. Many have been spontaneously communicating with animals since childhood, while others have developed their capacities to do so as adults, receiving mentoring from professional animal communicators and animals themselves. In step with the efforts of scholars who seek to challenge 'the ontological limits of what is legible as western scholarship' (Barker and Pickerill, 2020; Hunt, 2014: 27; Sepie, 2017), this research looks to alternative ways of knowing advanced by animal communicators.

\section{Situating ourselves}

We write this chapter as researchers interested in understanding the practices of IIC, and as humans who experience the phenomenon, to various degrees, as a tangible reality in our lives. We recognize that our present interspecies relational orientations shape understandings of ourselves, other animals, diverse practices of interspecies communication and the role of our respective fields in 
supporting a sustainable diversity of species. They also affect how we conduct our analyses and the suggested 'pathways' we offer for charting a way forward in step with other animal subjects.

Barrett, a settler-descendent interdisciplinary environmental scholar and University of Saskatchewan project lead, began receiving spontaneous communications from animals in 2005. Since then she has developed this capacity through careful study and attentive awareness. Her recent community-engaged research with local First Nations Elders, community members and colleagues recognizes the strengths of both Cree Elders' and animal communicators' approaches in strengthening interspecies relations (McGinnis et al., 2019). Doctoral candidate Hinz grew up in the German countryside and has been blessed to experience many moments of feeling connected and welcomed 'home' in nature. She is deeply curious about IIC, while also actively grappling with how it challenges anthropocentric worldviews and sterile notions of the removed observer, in which her previous natural scientific training was embedded. After taking several IIC classes, she is beginning to grasp intuitive communication with animals as something that may not just happen to her in isolated incidents, but may be tapped into intentionally. Wijngaarden, a senior research associate at the University of Johannesburg, experienced several isolated moments of IIC while training and travelling with horses, and during meditative moments in nature. During her ethnographic research with various animal communicators in Europe and Africa, she came to understand and exercise IIC she had spontaneously experienced, more as a skill she may access at will, but one that needs practice in order to be solidified and deepened. Lovrod, who grew up in a small-farming family, has come to understand how she benefited profoundly from her childhood on the land. She takes seriously the ways that the land's potential to sustain ecosystems - when stolen from Indigenous peoples - was severely compromised by colonialist and neoliberal investments in growth economics, which continue to threaten planetary biodiversities.

While there are many modes of communication among animals and humans, IIC presents as a detailed, non-verbal and non-physical form of communication between humans and other animals. Drawing on a diversity of intuitive capacities, IIC includes the mutual exchange of visceral feelings, emotions, mental impressions and thoughts, embodied sensations of touch, smell, taste, sound, as well as visuals in the mind's eye. While these exchanges can occur while in direct physical proximity to the animal, they can also occur over great distances and without the need for visual, auditory, olfactory, voice or other cues that humans normally associate with direct interactive communication. Therefore, the practice is often referred to as telepathic - coming from the 
Greek words, tele, which means 'far away' or 'distant', and patheia, which means 'feeling or perception' (Vittitoe, 2005: 37). While to some the word 'telepathy' suggests a super-skill available only to a select few with special abilities, it is a common intersubjective communication experience for many people the world over. These include Indigenous peoples, for many of whom, practices of interspecies communication are fully integrated into and supported by culturally informed knowledge systems and locally specific protocols (Deloria, 2006; Michell, 2005; Watts, 2013).

\section{Calling for alternative methods}

Attending to the experience of IIC as a possible pathway to deepen understandings of animals' perspectives, and to support the flourishing of all beings, responds to growing calls for epistemological innovation and ontological diversity in animal geographies and other interdisciplinary studies (Buller, 2015; Sepie, 2017; Van Dooren et al., 2016). It also responds to calls for cognitive and interspecies justice (Chilisa, 2012; Connell, 2014; Moichela, 2017). Scholars across many disciplines and cultural orientations have called for cognitive justice in their struggle to decolonize dominant knowledge frames and their impacts (de Sousa Santos, 2018; Hoppers, 2001; Visvanathan, 2009). Underlining the right for a multitude of knowledges to exist, be valued and be used, they have recognized that all knowledge is partial, and have embraced the critical and corrective potential that emerges through interactions among different knowledges. These calls for cognitive justice are related not only to struggles for local and global social justice for humans, but also across species and spaces.

IIC is a methodological and political venture that is, at the same time, highly personal. It challenges (and invites) researchers and learners of the method to understand and engage with animals as social peers, communicative partners and co-researchers. Many scholars have been exploring how recognizing the subjectivity of all beings is foundational to engaging in trans-species, social, cognitive and environmental justice. They ask how to disrupt human exceptionalism and ideological investments in the human-nature divide, which are often recognized as a key component of contemporary systems, requiring decolonization (Hovorka, 2017). Additionally, when many feminist, critical animal studies and animal geographies scholars attend to the 'Animal question', they begin by recognizing humans as animals too, and centre other species as co-subjects and beneficiaries of their research (Dowling et al., 2016; Gaard, 2012). Many of these accounts recognize the shared co-constituting 
nature of animal-human relations, and the need for a 'trans-species episteme' (Castricano, 2016: 249) that acknowledges animals 'as active participants in knowledge production and strive[s] to decrease the distance between us and the animal subjects we study' (Hovorka, 2015: 10).

Animal geographies' focus on the importance of 'exploring and documenting shared and embodied encounters with animals' (Buller, 2015: 378; Gibbs, 2019; Greenhough and Roe, 2019), as well as the field's calls for interspecies methods, highlight the challenges of and need for recognizing, appreciating and understanding the experiences of other animals. In response, innovative approaches, including non-representational methods, video, sometimes in combination with still photos, phenomenology and scrupulous practices of witnessing, have emerged (Buller, 2015; Gibbs, 2019). In their recent book, Ethnography after Humanism, Hamilton and Taylor (2017) speak to the importance of sensory methods and listening for the voices of animals. Similarly, in their ongoing intercultural work and writing with the more-than-human, Dowling et al. (2016) provide a set of innovative methodological possibilities for reimagining and reframing interspecies relations. Many of these approaches are explicit attempts to access the experience of the animal(s) in question more directly. Despite the increase in popular use of related practices, these scholars all remain silent about animal communicators and their applied methods to engage in direct, dialogical mutuality with animals.

Amidst increasing needs for: (1) non-objectifying approaches that pay careful attention to animal cognition, consciousness and language (Urbanik, 2018); and (2) stronger multispecies methods (Bear, 2017; Buller, 2015; Gibbs, 2019; Whatmore, 2006), we take up Whatmore's (2006: 606-607) call to 'amplify other sensory, bodily and affective registers and extend the company and modality of what constitutes a research subject. It is time to generate "voice" by using other senses and utilizing practices beyond the academy to do so'. With this in mind, we turn our attention to what can be known and learned about IIC, as practised by professional animal communicators.

\section{Animal communicators as mentors and interpreters}

Although we recognize the widespread occurrence of intuitive forms of communication with animals, our present research is primarily focused on IIC as it is practised, and learned, from those who work professionally as animal communicators. Often guided by a set of ethical protocols established by animal communicator Penelope Smith (2004) in the 1970s, they do not offer animals 
a voice, but use their carefully developed intuitive skills to listen actively to what animals have to say. These individuals engage deliberately with other animals as social peers and may become important mentors and interpreters for engaging IIC in interspecies research.

As represented in a survey of 93 animal communicators' websites conducted in 2018 (Barrett et al., 2018), those who present themselves as professionals in IIC come from a wide variety of educational backgrounds and fields, in roles such as: musician, nurse, equestrian, technical writer, medium and tarot advisor, graphic designer, geotechnical engineer, actor, chef, metaphysical minister, counsellor, teacher, zoo keeper, mechanic, radio newscaster, marketer and manager, to name a few. Cultural backgrounds are varied, and although many refer to notions of spirit when they describe their practice, very few situate their work within an established religion. Past education among animal communicators ranges from no post-secondary degrees to completed $\mathrm{PhDs}$, in areas as diverse as psychology, theatre, social work, genetics, business, fine arts, education, veterinary technology, and alternative medical practices such as reflexology and homeopathy. Animal communicators are located on all continents except Antarctica, with a particularly high concentration in the United States.

Working either as paid consultants or volunteers, they are most often called upon to assist in understanding animals' perspectives on behavioural, health and other concerns, and to assist in resolving conflicts between animals and people. Animal communicators commonly understand and frame IIC as something that is not restricted to a few gifted people, but rather, can be learned as a trained skill available to anyone. This framing is usually rooted in their own experience of learning IIC (sometimes from scratch) or teaching it to others (Barrett et al., 2018; Williams, 2003). Although an unregulated field, many animal communicators offer courses, workshops or full training programmes leading to practitioner certification.

To give the reader an idea of how IIC may be experienced, we offer several examples, described by animal communicators or their students. The first example stems from a research interview that Vittitoe (2005) conducted for her doctoral dissertation; the subsequent two examples are included in books written by animal communicators. The fourth example was reported during a research interview with co-author Vanessa Wijngaarden.

In this first example, the animal communicator (Sophie) ${ }^{3}$ is on the telephone with a couple who asked her to communicate, over distance, with their cat. This example illustrates a common flow of these kinds of communications. In 
this instance, Sophie initially doubted what the cat seemed to be conveying to her; however, the information made complete sense to the couple when she shared it with them:

I heard the words this time ... [The cat's] voice was very strong. It almost felt like he was yelling at me. When I asked him how he felt, he responded, 'Tell them about the turtle.' I thought I couldn't have heard that ... He repeated, 'Would you tell them about the turtle?' He was really getting upset ... The couple then told me about a wooden turtle they bought from a chainsaw sculptor. This cat enjoyed the turtle so much that he began using it as his own personal scratching post ... The couple asked me to find out what it was about the turtle that he wanted them to know. I got an image of a shaded place and everything being shadowy and dark and a feeling of frustration from the cat. The couple realized then that they had blocked access to the turtle by storing boxes in that room and the cat could not get to it. (Vittitoe, 2005: 87)

While participating in a workshop with animal communicator Amelia Kinkade (2006), a student of the practice reports her experience of a remote communication exercise with a cat (Sergio), who lived with another person participating in the workshop. Neither person had met one another before, and the person recounting this experience had never met Sergio, nor been to the person's home:

Suddenly, I could see into a room as if I were looking out of Sergio's eyes! I had a feeling that I had whiskers! I could clearly see whatever Sergio looked at as he turned his head. I asked him if there was anything bothering him, and he showed me a piano with a white cloth laid across the top. I asked him if it was the sound from the piano he didn't like, and he said, 'No, it's the cloth. It's too slippery when I jump on top of the piano.' ... I asked if he was missing anyone, and I got a sense that an orange cat was missing from his life ... I reported all this back to my [practice] partner, and it turns out it was all true! ... And she did have a piano with a white cloth on it! The cloth was often on the floor when she came home, and Sergio loved to sit up there on the piano. The orange cat was his brother, who had been ignoring him for a few weeks in favor of other cats in the house. (Kinkade, 2006: 42)

In her book, Communicating with Orcas: The Whales' Perspective, Getten (2006) recounts a communication session with an orca, Granny. She and Raphaela (another animal communicator with whom she worked) had been asking Granny about what is often referred to as 'spyhopping', when the whales come directly out of the water vertically. Getten writes:

Most of the time when I'm communicating with Granny, I get pictures from her or I hear words, but tonight I was getting a lot of bodily sensations ... Granny is letting me feel the water rushing off my body, my nose up in the air breaking the surface, the warm sun contacting my skin. It feels really wonderful. Then BOOM, an explosion of light, colour and activity! ... I could feel the water creating small wrinkles on 
the surface of her skin. The water pressure in the currents seemed to be physically moving my skin up and down. (Getten, 2006: 61)

Wynter Worsthorne has, since 2002, built up a reputation as a very successful professional animal communicator. She is often called upon to negotiate in conflicts between animals and people. One of these is a conflict with baboons near Cape Town, South Africa, where humans have been disturbed by baboons searching for food in the village; 25 out of the original troop of 28 adult baboons have been killed. Hired monitors were using paintball guns to control the baboons' movements, keeping them away from vehicle traffic and human residences. Worsthorne describes the communication with one of the baboons as follows:

\begin{abstract}
When I connected with her [the female baboon] on the night of the 4th May, the first feeling I had was one of exhaustion and a real heaviness to her body. I felt the weight of the [monitoring] collar, pressing down on the back of my neck and a heaviness in my shoulders. I also felt a pain in my stomach, much like how I experience nervous tension and anxiety in my own body. I then felt overwhelming grief at the loss of 'my baby' [which had been killed by a motorist] ... I explained that the reasoning behind the monitors keeping them [the baboons] away from the sea was to protect them from the cars. She then showed me an image of the monitors putting down their guns and picking up red flags to slow the cars down. The feeling that I got [from tuning into her] is that if the people really wanted to protect them, then the paintballing guns need to be put down and more care for their well-being by the people in charge would ensure their protection.
\end{abstract}

While there are many books written by animal communicators, there is little scholarly research on them or their practices. At the time of writing, and after an extensive literature search, we identified just three research papers and two unpublished dissertations, from diverse fields. Using phenomenological ethnography, Hafen (2013) drew from participant observations in an interspecies communication workshop, together with follow-up interviews with workshop participants and four animal communication teachers. Her findings provide a general introduction to the practice, some insights into how participants experience IIC, and its impact on their relationships with their companion animals.

Using a mixed-methods approach situated within the field of parapsychology, Erickson has led two studies. One is focused on dogs (Erickson, 2014), interrogating the accuracy of information received remotely from an animal communicator, as assessed by each animal's human caretaker. The second (Erickson et al., 2016), assesses the usefulness of animal communicators' reports about remote communications with 12 therapeutic riding horses, given to and rated by the guardians of these horses and the war veterans with whom they 
worked. In both studies, the applied Likert scale ratings showed high levels of accuracy and usefulness, respectively: 5.12/6 in the 2014 study, and 5.75/6 in the 2016 study (Erickson et al., 2016). In the 2016 study, the participating animal communicators were also asked to include a standard question about potential mouth pain in their communications with the horses. In comparison with a subsequent dental exam conducted by a veterinarian who had remained uninformed of the outcomes of the communications, Erickson et al. (2016) found that, in all cases, the animal communicators reported correctly which of the horses were in need of dental treatment.

In the field of human and organizational systems, Vittitoe (2005: 59) explored the experience of 'becoming and being an animal communicator', by conducting seven interviews with animal communicators, then analysing the narratives to identify common themes in motivation, experience, making sense of the phenomenon, and its transformational impact. Trans-species psychologist Gay Bradshaw (2010) does mention IIC, but animal communication practices are not explored in her work. A recent overview of the field of human-animal communication research published in the Annual Review of Anthropology highlighted animal communicators and their practices as an important area for future study, while simultaneously disparaging them and their profession (Kulick, 2017). The published comments reveal deeply gendered and epistemological prejudices that reflect tendencies to dismiss experiences that are deemed 'extraordinary' within modern Western scientific framings, but which are familiar in other contexts and worldviews (Deloria, 2006; Young and Goulet, 1994). Such misrepresentations may point to some of the reasons why animal communicators are not yet well represented in multispecies methodological discussions. It is often because of dismissive and stigmatizing judgements that large segments of human experience become unavailable 'for discussion and scientific investigation' (Young and Goulet, 1994: 8), even though such experiences might be quite common among scientists and others (see also Hafen, 2013; Nadasdy, 2007).

\section{Next steps for animal geographers: ask the animals}

IIC takes 'animal circumstances, experiences, and standpoints' seriously (Hovorka, 2015: 389). It not only acknowledges animals as active partners in knowledge production, but also offers, through the translation capacities of animal communicators, methods to facilitate more equitable collaborations. Attending to IIC as both research topic and transformative method provides rich potentials for foregrounding animal voices, shifting interspecies 
relations and contributing to wider ontological, epistemological and decolonial debates that address harmful power imbalances arising from multiple, interwoven exceptionalist systems. As we engage in this scholarly work, we have identified a set of considerations as relevant to IIC research, not least of which is the potential for disrespectful manipulation of animal needs and misrepresentations of human-animal interests. These considerations have emerged and crystallized for us within our respective research projects, our own engagements with IIC, and while thinking critically and reflexively about our research.

IIC challenges deeply inscribed Cartesian dualisms by disestablishing absolutist understandings of the dichotomies of body/mind and nature/culture. Effective application of IIC calls for interspecies humility; it is a conversation between equals. It requires defamiliarization with and disidentification from (Muñoz, 1999) hierarchical systems that facilitate aggression among humans and across species, based on claims to the exceptional importance of prevailing economic, military or, indeed, academic systems. Searching for ways to bring animal voices into practice means that scholars will need to be open and receptive to transformations that may, at times, involve their whole being and cannot be neatly contained and left at the 'research bench'. When engaging IIC, it matters who and 'how' we 'are' (our be-ing) as researchers and humans, and where we stand in relational exchanges in our lives. Researchers will benefit from developing a personal 'literacy' in diversely embodied ways of being and doing, especially those that emphasize relationality across ways of knowing. This can inspire new perspectives and ways of seeing (in theory, methodology and understanding of data), ensure that experiential dimensions of IIC are not overlooked or misunderstood, and support researchers in stepping out of hierarchical patterns that are otherwise self-reinforcing. As an example, animal communicators may describe experiencing in their own bodies and minds what the animal is experiencing or communicating to them. In extreme cases, this can lead to experiences for which the animal communicator has no point of reference based on their own human body, such as experiencing a dog's extremely strong sense of smell, or what it is like to have fur and a tail. Experiences like these blur dualistic lines among individuals, animal and human, and often challenge or exhaust the vocabulary of those trying to describe them (Hinz, forthcoming).

The ethical and practical problems arising from the onslaught of environmental and interspecies violence induced by human exceptionalisms may be addressed through practising a radical multivocality (Wijngaarden and Idahosa, 2021) that engages a broader range of human and animal subjects in the process of scientific knowledge production. While one can certainly study 
the practice of IIC as an outsider, to take up the method requires engaging in both epistemological and ontological stretching, as the risks of imposing preconceived ideas on the practice are high. Hence, we have found it useful to follow the anthropological practice of 'radical participation' (Nadasdy, 2007) by learning IIC ourselves, in order to better understand the phenomenon from the inside. Our in-process journeys have included: taking courses from experienced animal communicators; practising to deepen our skills and critical understandings of IIC; reflecting on the ways in which our positionalities as academics may inadvertently reinscribe the power systems that we are attempting to disrupt; questioning the many ways in which academic constraints and reductive worldviews contribute to internalized silencing of our capacities to hear animal voices; and practising greater humility and reflexivity while becoming increasingly skilled in identifying where individual issues, perceptions and fears distort clear communications. In doing this research, we have collaborated directly with professional animal communicators. We have also worked respectfully with Cree Traditional Knowledge Keepers (Joseph Naytowhow) and Elders (Stewart Prosper, Yvonne Chamakese and the Beardy's Okemasis First Nation Elder's Research Advisory Group) in Canada; Mandaza, a Shona shaman in Zimbabwe; and KhoiSan communities in South Africa. Still in its early stages, this collaborative intercultural research has helped to identify both resonances with, and differences among, Indigenous practices and those used by non-Indigenous animal communicators.

Critical reflexivity about our human multilayered embeddedness in socio-political, epistemological and ontological orientations renders animal subjects more visible to us. Growing insights about individual and collective animal subjectivities (Proctor et al., 2013) highlight the urgency for cognitive justice to be extended to other animals. Researchers need to stay aware that "methods not only describe but "enact" the world they purport to study ... [They] help to both create and re-create the social world, that they are produced by and productive of that world' (Taylor and Hamilton, 2014: 255f.). We propose critical investigation into practical applications of IIC in interspecies knowledge development as a way to be inclusive of animal voices, decolonize research methodologies and adopt wider solidarities with animals, peoples and places most affected by prevailing exceptionalisms. We also recognize the need for such engagements to resist the unethical misuse of IIC in any 'moves to innocence' (Tuck and Yang, 2012) that might falsely affirm animals' consent for species extinctions linked to neoliberal emphasis on unlimited economic growth. Diverse species and individual animals bring multiple perspectives and ways of vocalizing ideas. Research in and use of IIC as a method crosses normative lines of power, privilege, competing epistemologies, ontologies and 
ethics, and consistently disrupts many ways of knowing and being that dominate much of modern Western culture.

Researching IIC invites us to revisit approaches to cognitive justice by engaging the perspectives of the animals themselves. Our various studies across disciplines are geared to promote future collaborations that investigate the use of IIC as a practical, ethical and transformative method to conduct research with, rather than on animals, engaging them as consenting and communicative research participants. Our current research investigates how the practice of IIC disrupts the marginalizations of peoples, places and species that continue to shape Western knowledge production. At the University of Saskatchewan we are preparing groundwork manuscripts including an environmental scan of animal communicators and their professional ethics; an analysis of the impacts of interspecies communications on human and other animal subjectivities; implications for intercultural collaborations involving Indigenous and non-Indigenous groups; and a descriptive phenomenological study providing in-depth understanding of what animal communicators do and experience. Throughout, we consider what it means to engage with animal collaborators as agents and research participants, for example by conveying, via animal communicators, a sense of the study's purpose and inquiring about the animal's research consent before continuing intuitive communications that are part of various data collection processes. Since November 2017, Wijngaarden has experimented methodologically with interviewing animals as research participants by employing animal communicators as interpreters, mostly working with domesticated and wild felines. After further data collection and analysis, she expects to publish results as part of her ongoing study on 'Traversing the nature/culture divide: multispecies strategies and relational approaches to knowledge production'. These research endeavours demand more of us as humans. Conscious engagement with multispecies relational research has the potential to transform who we are, our understanding of who other animals are, and who we can be together.

\section{Conclusion}

Openness to examining and practising intuitive forms of communication across species is a necessary diplomacy in seeking interspecies cognitive justice. Animal geographers are uniquely situated to address cognitive justice for animals by examining the impacts of anthropocentric and exceptionalist systems with particular attention to human accountabilities for mutual flourishing across species and spaces. IIC provides an important method and way 
of being with animal collaborators that may open possibilities for them to engage in knowledge-building as collaborators and co-researchers. Potential directions for related animal geographies' research into IIC is expansive.

Some starting points for investigation include taking up questions such as: How does IIC work and for what purposes of interest to animal geographers? How does it manifest across cases examined? What are the resonances and dissonances across diverse cultures and ways of knowing, including but not limited to Indigenous cultures? What is the animal subject's experience and to what degree can humans legitimately claim to understand it? Are there risks? For animals? For humans? What are the ethical implications? Could IIC lead to 'informed consent' for animals involved in research and other endeavours, such as wildlife management and regional and urban planning? Can studying IIC provide insights into anthropomorphism in the lived experiences of wild and domestic animals? What would be mechanisms of action that support ethical deployment of IIC in academic research? What are the implications for contemporary epistemologies, ontologies and axiologies, and for application of new laws recognizing the Rights of Nature? How might IIC challenge Cartesian dichotomies and the decontextualizations of research underlying scientific knowledge-making? And what does the practice of IIC mean for day-to-day interactions with the many animals with whom we share this planet?

\section{Acknowledgements}

We offer our deepest gratitude to the human and more-than-human communities and lands with whom we have worked, including all animals, animal communicators, Elders, Traditional Knowledge Keepers and Ancestors. We thank them for their contributions to our collective learning.

We also acknowledge the following for funding. In South Africa, University of Johannesburg Global Excellence Stature Fellowship (Communication Studies Department) and Dean of Humanities Office. In Canada, the Social Sciences and Humanities Research Council of Canada (SSHRC); Beardy'sOkemasis First Nation; University of Saskatchewan - President's SSHRC, Interdisciplinary Centre for Culture and Creativity, Community-Engaged Scholar's Grant, international Dean's Scholarship, and School of Environment and Sustainability PhD Scholarship. 


\section{Notes}

1. We recognize that we, as humans, are one of many animal forms. Throughout the chapter, we use the term 'animal' to refer to species other than our own, avoiding language complexities and centring acts related to words such as 'non-human animals'. We write as humans, and when we are referring to a particular other animal species, we use that species name.

2. Current definitions and descriptions of IIC are evolving.

3. 'Sophie' is a pseudonym, as are all names of participating animal communicators in Vittitoe's (2005) study.

\section{References}

Anderson, K. (2014). Mind over matter? On decentring the human in human geography. Cultural Geographies, 21(1), 3-18. http://doi.org/10.1177/1474474013513409.

Barker, A.J., and Pickerill, J. (2020). Doings with the land and sea: decolonising geographies, Indigeneity, and enacting place-agency. Progress in Human Geography, 44(4), 640-662. https://doi.org/10.1177/0309132519839863.

Barrett, M.J., Montgomery, J., and Hinz, V. (2018). More-than-human methodologies and the ontological turn: engaging with intuitive interspecies communication as multi-species method. Paper presented at Canadian Association of Geographers Annual Meeting, Québec, Canada.

Bear, C. (2017). Assembling ocean life: more-than-human entanglements in the blue economy. Dialogues in Human Geography, 7, 27-31.

Blenkinsop, S., Affifi, R., Piersol, L., and De Danann Sitka-Sage, M. (2017). Shut-up and listen: implications and possibilities of Albert Memmi's characteristics of colonization upon the 'natural world'. Studies in Philosophy and Education, 36(3), 349-365. https://doi.org/10.1007/s11217-016-9557-9.

Bradshaw, G. (2010). You see me, but do you hear me? The science and sensibility of trans-species dialogue. Feminism and Psychology, 20(3), 407-419. https://doi.org/10 $.1177 / 0959353510368285$.

Buller, H. (2015). Animal geographies II: methods. Progress in Human Geography, 39(3), 374-384. https://doi.org/10.1177/0309132514527401.

Castricano, J. (2016). Rampant compassion: a tale of two anthropomorphisms and the 'trans-species episteme' of knowledge-making. In J. Castricano and L. Corman (eds), Animal Subjects 2.0 (pp. 249-268). Waterloo, ON: Wilfrid Laurier University Press.

Chilisa, B. (2012). Indigenous Research Methodologies. Thousand Oaks, CA: SAGE Publications.

Connell, R. (2014). Using southern theory: decolonizing social thought in theory, research and application. Planning Theory, 13(2), 210-223.

de Sousa Santos, B. (2018). The End of the Cognitive Empire: The Coming of Age of Epistemologies of the South. Durham, NC: Duke University Press.

Deloria, V. (2006). The World We Used to Live In: Remembering the Powers of the Medicine Men. Golden, CO: Fulcrum Publishing. 
Dowling, R., Lloyd, K., and Suchet-Pearson, S. (2016). Qualitative methods II: 'more-than-human' methodologies and/in praxis. Progress in Human Geography, 41(6), 823-831. https://doi.org/10.1177/0309132516664439.

Erickson, D.L. (2014). A mixed methods exploratory study of alleged telepathic interspecies communication with domestic dogs (Canis lupus familiaris). Unpublished doctoral dissertation, Saybrook University, Pasadena, CA.

Erickson, D.L., Fisher, D., Woelk, B., Buckner, W., and Ashley, C. (2016). A mixed methods study of telepathic interspecies communication with therapeutic riding horses and their recovering wounded veteran partners. NeuroQuantology, 14(2), 404-427.

Fawcett, L. (2000). Ethical imagining: ecofeminist possibilities in environmental learning. Canadian Journal of Environmental Education, 5, 134-149.

Gaard, G. (2012). Feminist animal studies in the US: bodies matter. DEP: Deportate, esuli, profughe, 20, 14-21.

Getten, M.J. (2006). Communicating with Orcas: The Whales'Perspective. Charlottesville, VA: Hampton Roads Publishing Company.

Gibbs, L.M. (2020). Animal geographies I: hearing the cry and extending beyond. Progress in Human Geography, 030913251986348. http://doi.org/10.1177/ 030913251986348.

Greenhough, B., and Roe, E. (2019). Attuning to laboratory animals and telling stories: learning animal geography research skills from animal technologists. Environment and Planning D: Society and Space, 37, 367-384.

Hafen, S. (2013). Listening with the third eye: a phenomenological ethnography of animal communicators. In Emily Plec (ed.), Perspectives on Human-Animal Communication: Internatural Communication (pp. 185-206). London: Routledge. https://doi.org/10.4324/9780203082935.

Hamilton, L., and Taylor, N. (2017). Ethnography after Humanism: Power, Politics and Method in Multi-Species Research. London: Palgrave Macmillan.

Haraway, D. (2004). Otherworldly conversations; terran topics; local terms. In Donna J. Haraway (ed.), The Haraway Reader (pp. 125-150). New York: Routledge.

Haraway, D. (2008). When Species Meet. Minneapolis, MN: University of Minnesota Press.

Hinz, V.F. (forthcoming). Understanding the lived experience of intuitive interspecies communication: a phenomenological study. Doctoral dissertation, University of Saskatchewan.

Hoppers, C.A.O. (2001). Indigenous knowledge systems and academic institutions in South Africa. Perspectives in Education, 19, 73-86.

Hovorka, A.J. (2015). The Gender, Place and Culture Jan Monk Distinguished Annual Lecture. Feminism and animals: exploring interspecies relations through intersectionality, performativity and standpoint. Gender, Place and Culture, 22(1), 1-19. http://doi.org/10.1080/0966369X.2014.993546.

Hovorka, A.J. (2017). Animal geographies I. Progress in Human Geography, 41(3), 030913251769992. http://doi.org/10.1177/0309132517699924.

Hunt, S. (2014). Ontologies of Indigeneity: the politics of embodying a concept. Cultural Geographies, 21(1), 27-32. https://doi.org/10.1177/1474474013500226.

Kinkade, A. (2006). The Language of Miracles: A Celebrated Psychic Teaches You to Talk to Animals. Novato, CA: New World Library.

Kulick, D. (2017). Human-animal communication. Annual Review of Anthropology, $46,357-378$. 
Lorimer, H. (2010). Forces of nature, forms of life: calibrating ethology and phenomenology. In B. Anderson and P. Harrison (eds), Taking-Place: Non-representational Theories and Geography (pp. 55-78). Farnham: Ashgate Publishing.

McGinnis, A., Kincaid, A., Barrett, M.J., Ham, C., and Community Elders Research Advisory Group (2019). Strengthening animal-human relationships as a doorway to Indigenous holistic wellness. Ecopsychology, 11(3), 162-173. https://doi.org/10 $.1089 /$ eco.2019.0003.

Michell, H. (2005). Nēhîthâwâk of Reindeer Lake, Canada: worldview, epistemology and relationships with the natural world. Australian Journal of Indigenous Education, 34, 33-43.

Moichela, K.Z. (2017). Integration of indigenous knowledge systems in the curriculum for basic education: possible experiences of Canada. Unpublished doctoral dissertation, University of South Africa, Pretoria.

Muñoz, J.E. (1999). Disidentifications: Queers of Color and the Performance of Politics. Minneapolis, MN: University of Minnesota Press.

Nadasdy, P. (2007). The gift in the animal: the ontology of hunting and human-animal sociality. American Ethnologist, 34(1), 25-43. https://doi.org/10.1525/ae.2007.34.1 .25

Proctor, H.S., Carder, G., and Cornish, A.R. (2013). Searching for animal sentience: a systematic review of the scientific literature. Animals, 3(3), 882-906.

Sepie, A.J. (2017). More than stories, more than myths: animal/human/nature(s) in traditional ecological worldviews. Humanities, 6(4), 78-109. https://doi.org/10.3390/ h6040078.

Smith, P. (2004). When Animals Speak: Advanced Interspecies Communication. San Francisco, CA: Council Oak Books.

Taylor, N., and Hamilton, L. (2014). Investigating the other: considerations on multi-species research. Studies in Qualitative Methodology, 13, 251-271. https://doi .org/10.1108/S1042-319220140000013016.

Tuck, E., and Yang, K.W. (2012). Decolonization is not a metaphor. Decolonization: Indigeneity, Education and Society, 1(1), 1-40.

Urbanik, J. (2018). Geographies of nonhuman animal communication and language. In S. Brunn and R. Kehrein (eds), Handbook of the Changing World Language Map (pp. 1-16). Cham: Springer International Publishing. http://doi.org/10.1007/978-3 -319-73400-2_93-1.

Van Dooren, T., Kirksey, E., and Münster, U. (2016). Multispecies studies: cultivating arts of attentiveness. Environmental Humanities, 8(1), 1-23.

Visvanathan, S. (2009). The search for cognitive justice. Retrieved from http://www .india-seminar.com/2009/597/597_shiv_visvanathan.htm.

Vittitoe, B.J. (2005). Becoming and being an animal communicator: a phenomenological study. Unpublished doctoral dissertation, Fielding Graduate University, Santa Barbara, CA.

Watts, V. (2013). Indigenous place-thought and agency amongst humans and non-humans (First Woman and Sky Woman go on a European world tour!). Decolonization: Indigeneity, Education and Society, 2(1), 20-34.

Whatmore, S. (2006). Materialist returns: practising cultural geography in and for a more-than-human world. Cultural Geographies, 13(4), 600-609. http://doi.org/10 $.1191 / 1474474006$ cgj377oa.

Wijngaarden, V., and Idahosa, G.E. (2021). An integrated approach towards decolonising higher education: a perspective from anthropology. In I. Turner, E. Woldegiorgis and A. Brahima (eds), Indigenous Knowledges and Decolonisation in 
Higher Education: Current Discourses, Pertinence and Prospects (pp. 36-59). London: Routledge.

Williams, M. (2003). Learning their Language: Intuitive Communication with Animals and Nature. Novato, CA: New World Library.

Young, D.E., and Goulet, J.-G. (1994). Introduction. In D.E. Young and J.-G. Goulet (eds), Being Changed by Cross-Cultural Encounters: The Anthropology of Extraordinary Experience (pp. 7-13). Peterborough, ON: Broadview Press. 
M.J. Barrett, Viktoria Hinz, Vanessa Wijngaarden, and Marie Lovrod - 9781788979993 Downloaded from PubFactory at $04 / 26 / 2023$ 11:12:06AM 